\section{Rape in South Africa - call to action}

To the Editor: After reading the above-titled editorial, ${ }^{[1]}$ I came to the conclusion that it gave a historical perspective, by and large, to the care of rape victims in South Africa. It contains many criticisms of practitioners who care for such victims:

- 'secondary trauma sometimes suffered at the hands of the SAPS and health services

- many rape survivors feel alone and let down by ... the institutions that ostensibly exist to protect them

- four rape crisis centres ... there has been no significant change to the quality of services offered to rape survivors

- misapprehension ... medical staff ... victims must first lay a charge

- lack of clinical competence in clinical forensic medicine, all compounded by staff apathy, resistance and non-adherence to protocols.'

I agree that the quality of care of rape victims varies from institution to institution, but absolutely no mention is made of the increasing number of centres of excellence for the care of rape victims, and victims of child and elderly abuse. I run such a centre and find the general assertions about health services and their staff in regard to rape victims totally off the mark.

No mention is made of the existence, and ongoing introduction and development of, Thuthuzela Care Centres (TCC). The Cabinet initiated an initiative in 2000 to develop a comprehensive anti-rape strategy. This was initially the responsibility of the Departments of Health and Social Development, and later the Departments of Justice and Constitutional Development. These collaborated with the Treasury and the Departments of Education, and Safety and Security, to form the Interdepartmental Management Team (IDMT) chaired by the National Prosecuting Authority (NPA). The IDTM in turn developed the model of the TCC. Our unit was funded by a grant from the Danish government through UNICEF, as were many other TCCs. We offer a 24/7 service, turn no-one away, regardless of where they come from, whether they have reported to the police or are selfpresenting, and whether they need all our services or only medication, say. To use a common term, we are a 'one-stop shop' for we also have onsite NPA staff members; a site co-ordinator and a victim assistance officer, a female non-uniformed officer from the SAPS, and a hospital social worker. Our nursing operations manager is a qualified forensic nurse able to examine victims and give evidence in regional magistrates courts and high courts. The NPA has a qualified advocate as the case manager at our local court, purely to look after our cases and their dockets. We work very closely with the two Family Violence, Child Protection and Sexual Assault (FCS) units in our area; they have an excellent record of apprehending perpetrators.

Victims who come to us are reassured, comforted and cared for. The whole process is explained to them before any procedures commence, and they are urged to ask questions whenever they wish. The time it takes for the examination is the time it takes anything from 2 - 3 hours for a new case. Extensive general and specific histories are taken. They are seen by HIV counsellors who perform testing if permission is given. We do a complete collection of forensic evidence, complete all medico-legal documentation in fine detail, and give victims prophylaxis for HIV, STDs and pregnancy, as appropriate. We liaise with a placement agency and, if necessary, admit victims until their safety can be ensured. We have bathrooms so that victims can clean up and start the long path from victim to survivor. We supply 'comfort kits' with all necessary washing items and clean underwear. We also keep stocks of blankets and secondhand clothing to issue as needed; these items are donated by church groups, Rotary etc. as a result of our ongoing talks and relations with them. Victims are supplied with cards detailing all their return dates plus our phone number. We aim to ensure that all victims see social workers and hospital psychologists, where necessary. We assure victims that they can return to us at any time if problems develop medical, social and legal.

There are specific protocols, both national and provincial, that govern our activities. The TCC is subject to audit via the Woman's Justice and Empowerment Initiative using guidelines for selfassessment and action planning. We have developed site-specific protocols. We meet monthly with a wide range of roleplayers under the auspices of the local South African Police Services at an AntiRape Strategy and Integrated Sector Meeting, followed by a TCC Implementation Meeting.

Part of our protocols demands that we are strongly involved in outreach activities. We conduct many; e.g. as we knew there was a real need to educate school children about rape, respect and how to react to various forms of abuse, we initially went to individual schools to present talks, but found this was not efficient. Therefore, sponsored by, and with the co-operation of, other government and municipal departments, we have so far held 2 2-day seminars for teachers, 1 from each school, so they can then pass the message to the other teachers, and then to the pupils at those schools. Attendance was between 150 and 200 for each seminar.

Our hope is that, through outreach and the services we supply, we shall see increasing numbers of rape victims, not because the absolute numbers are increasing but because more and more unreported cases will present.

There are now 7 TCCs in KwaZulu-Natal.

\section{Gerald Baldrey}

Department of Clinical Forensic Medicine, Port Shepstone Regional Hospital, Port Shepstone, South Africa

mwbrain@mweb.co.za

1. Naidoo K. Rape in South Africa - call to action. S Afr Med J 2013;103(4):210-211. [http://dx.doi. org/10.7196/SAMJ.6802]

S Afr Med J 2013;103(8):498. DOI:10.7196/SAMJ.7204 